\title{
Screening of key genes in gastric cancer with DNA microarray analysis
}

\author{
Yong Jin and Wei $\mathrm{Da}^{*}$
}

\begin{abstract}
Background: The aim of this study was to identify key genes and novel potential therapeutic targets related to gastric cancer (GC) by comparing cancer tissue samples and healthy control samples using DNA microarray analysis.

Methods: Microarray data set GSE19804 was downloaded from Gene Expression Omnibus. Preprocessing and differential analysis were conducted with of $R$ statistical software packages, and a number of differentially expressed genes (DEGs) were obtained. Cluster analysis was also done with gene expression values. Functional enrichment analysis was performed for all the DEGs with DAVID tools. The significantly up- and downregulated genes were selected out and their interactors were retrieved with STRING and HitPredict, followed by construction of networks. For all the genes in the two networks, GeneCodis was chosen for gene function annotation.

Results: A total of 638 DEGs were identified, and we found that SPP1 and FABP4 were the markedly up- and downregulated genes, respectively. Cell cycle and regulation of proliferation were the most significantly overrepresented functional terms in up- and downregulated genes. In addition, extracellular matrix-receptor interaction was found to be significant in the SPP1-included interaction network.
\end{abstract}

Conclusions: A range of DEGs were obtained for GC. These genes not only provided insights into the pathogenesis of GC but also could develop into biomarkers for diagnosis or treatment.

Keywords: Differentially expressed gene, Functional enrichment analysis, Gastric cancer, Interaction network, Pathway analysis

\section{Background}

Gastric cancer (GC) is one of the most prevalent cancers in the world. Recognized risk factors for GC include infection with Helicobacter pylori, dietary factors, smoking and other factors [1]. Molecular genetics and molecular biology studies have shown that the pathogenesis of GC is a progressive process involving multiple steps and factors. The activation, overexpression or amplification of oncogenes and the deletion or mutation of tumor suppressor genes play important roles in the development of GC [2]. Molecularly targeted therapy holds promise and thus has become a focus in the field of cancer treatment in recent years [3]. Biomarkers can be used clinically to predict the effectiveness and toxicity of anticancer drugs and thus help to achieve individualized treatment [4].

\footnotetext{
* Correspondence: d_a_w_e_i@hotmail.com
}

Department of gastroenterology, The 6th People's Hospital affiliated to Shanghai Jiaotong University, No. 600 Yishan Road, Shanghai 200233, China
Ryu et al. found seven overexpressed proteins and seven underexpressed proteins in GC by using a proteomics approach [5]. Jang et al. also tried to identify biomarker candidates by analyzing proteome profiles [6]. Yasui et al. performed serial analysis of gene expression to search for new biomarkers [7]. Accordingly, quite a few potential biomarkers have been reported, such as regenerating gene family member 4 [8], olfactomedin [9], resistin and visfatin [10]. However, current knowledge is not sufficient to conquer the disease clinically.

Microarray technology is a powerful tool with which to discover the comprehensive changes in the incidence and development of cancer [11]. Therefore, in this study, gene expression profiles of GC tissue samples and healthy controls were compared to identify differentially expressed genes (DEGs). By combining functional enrichment analysis and interaction network analysis in our study, we sought not only to provide insights into the pathogenesis

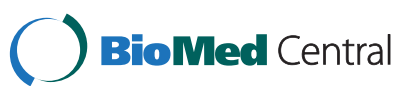

(c) 2013 Jin and Da; licensee BioMed Central Ltd. This is an open access article distributed under the terms of the Creative Commons Attribution License (http://creativecommons.org/licenses/by/2.0), which permits unrestricted use, distribution, and reproduction in any medium, provided the original work is properly cited. 
of GC but also to discover potential biomarkers for the diagnosis and treatment of GC.

\section{Methods}

\section{Microarray data}

Microarray data set GSE2685 [12] was downloaded from Gene Expression Omnibus (http://www.ncbi.nlm.nih.gov/ geo/) [GEO:GSE2685], including $22 \mathrm{GC}$ samples and 8 healthy controls. The GLP80 [Hu6800] Affymetrix Human
Full Length HuGeneFL Array (Affymetrix, Santa Clara, CA, USA) and the annotation information of probes were used to detect the gene expression.

\section{Differential expression analysis}

Raw data were converted into recognizable format, and missing values were imputed [13]. After data normalization [14], the multtest package [15] of $R$ software was chosen to perform statistical analysis to identify the DEGs by

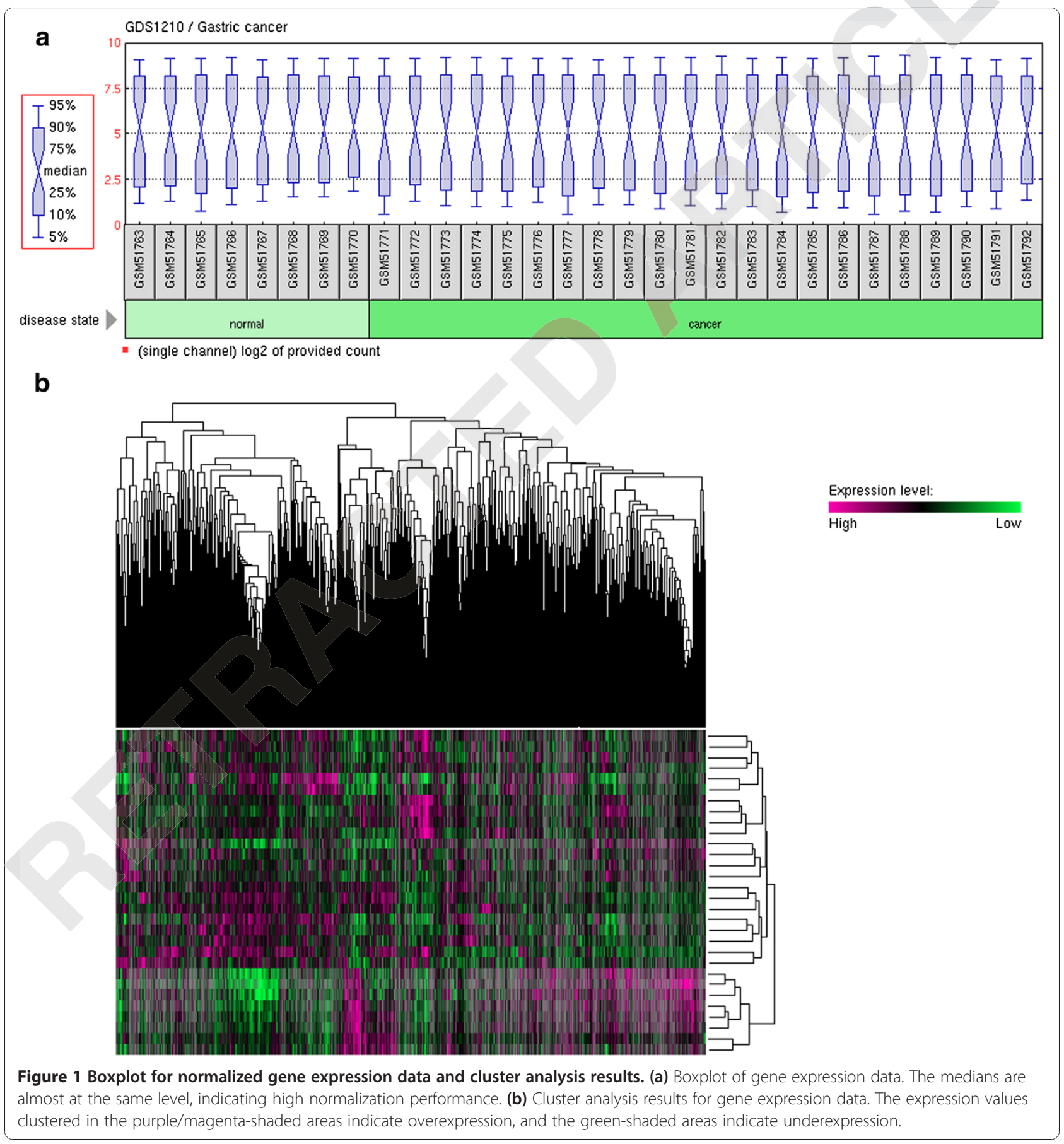


comparing them with healthy tissues, and multiple testing correction was done using the Benjamini-Hochberg method [16]. A false discovery rate (FDR) less than 0.05 and an absolute log fold change $(|\log F C|)$ greater than 1 were set as the significant cutoffs.

\section{Cluster analysis}

Cluster analysis [17] was conducted on the basis of the gene expression values in each sample to verify the difference in gene expression between GC tissue samples and healthy controls.

\section{Functional enrichment analysis for all differentially expressed genes}

Functional enrichment analysis is able to reveal biological functions based upon DEGs [18]. Therefore, in the present study, we chose to use the web-based DAVID database (Database for Annotation Visualization and Integrated Discovery) for functional annotation bioinformatics microarray analysis [19] to determine the functional enrichment and the Gene Ontology (GO) annotation, with $P<0.05$ were selected as the significant functions.

\section{Construction of interaction network}

Proteins usually interact with each other to display certain functions [20]. Therefore, interactors of the most significant DEGs were predicted, including the upregulated DEGs and downregulated DEGs using STRING (Search Tool for the Retrieval of Interacting Genes/Proteins) [21] and HitPredict software [22], then the interaction networks of the significantly upregulated DEGs and downregulated DEGs, respectively, with their interactors were established.

STRING connects major databases and predicts interactions based upon experiments, text mining and sequence homology. HitPredict collects interactions from databases such as IntAct (EMBL-European Bioinformatics Institute, Cambridge, UK) [23], BioGRID (Biological General Repository for Interaction Datasets) and HPRD (Human Protein Reference Database) [24], as well as from those predicted by algorithms [22]. The interaction network from HitPredict, which we obtained from experiments and the likelihood score greater than 1, were considered high-confidence interactions [25]. Interaction networks from STRING were obtained with a high degree of confidence.

Functional enrichment analysis for all genes in the network To explore the biological functions of all genes in the network we obtained previously, we chose GeneCodis software [26] for functional enrichment analysis. $P<0.05$ was applied as the cutoff value for significance.

GeneCodis (Gene Annotations Co-occurrence Discovery) is a web-based tool used for gene functional analysis [27-29]. It integrates different information resources (GO, KEGG (Kyoto Encyclopedia of Genes and Genomes) and
Swiss-Prot gene accession databases) to seek the annotation of genes and arrange their biological functions according to their significance.

\section{Results \\ Differentially expressed genes}

Normalized gene expression data are shown in Figure 1a. Good normalization performance was achieved. A total of 638 DEGs were screened out in GC samples compared with healthy controls, including 225 upregulated DEGs and 413 downregulated DEGs.

\section{Cluster analysis results}

Cluster analysis was performed with gene expression values, and the results are shown in Figure 1b. The gene expression of GC samples are distinguished from the

Table 1 Functional enrichment analysis of the upregulated and downregulated differentially expressed genes ${ }^{a}$

\begin{tabular}{|c|c|c|}
\hline Gene accession number & Count & FDR \\
\hline \multicolumn{3}{|l|}{ Upregulated DEGs } \\
\hline [GO:0022402] Cell-cycle process & 30 & $1.50 \mathrm{E}-05$ \\
\hline [GO:0007049] Cell cycle & 35 & 3.70E-05 \\
\hline [GO:0022403] Cell-cycle phase & 24 & $1.43 \mathrm{E}-04$ \\
\hline [GO:0000278] Mitotic cell cycle & 22 & $3.82 \mathrm{E}-04$ \\
\hline [GO:0007155] Cell adhesion & 30 & 0.00146 \\
\hline [GO:0022610] Biological adhesion & 30 & 0.001503 \\
\hline [GO:0006928] Cell motion & 24 & 0.001626 \\
\hline [GO:0042981] Regulation of apoptosis & 32 & 0.00271 \\
\hline [GO:0043067] Regulation of programmed cell death & 32 & 0.003334 \\
\hline [GO:0010941] Regulation of cell death & 32 & 0.0036 \\
\hline [GO:0006259] DNA metabolic process & 24 & 0.004784 \\
\hline [GO:0009611] Response to wounding & 24 & 0.010324 \\
\hline [GO:0001501] Skeletal system development & 18 & 0.013141 \\
\hline [GO:0051301] Cell division & 17 & 0.0199 \\
\hline [GO:0051726] Regulation of cell cycle & 18 & 0.021567 \\
\hline \multicolumn{3}{|l|}{ Downregulated DEGs } \\
\hline [GO:0042127] Regulation of cell proliferation & 48 & $3.72 \mathrm{E}-04$ \\
\hline [GO:0008284] Positive regulation of cell proliferation & 32 & 4.67E-04 \\
\hline [GO:0006873] Cellular ion homeostasis & 30 & 5.59E-04 \\
\hline [GO:0006955] Immune response & 43 & 0.001061657 \\
\hline [GO:0055080] Cation homeostasis & 25 & 0.001479293 \\
\hline [GO:0019226] Transmission of nerve impulse & 27 & 0.005126019 \\
\hline [GO:0019725] Cellular homeostasis & 32 & 0.005850539 \\
\hline [GO:0007610] Behavior & 32 & 0.006669845 \\
\hline [GO:0007586] Digestion & 13 & 0.009844162 \\
\hline [GO:0006875] Cellular metal ion homeostasis & 19 & 0.010226535 \\
\hline [GO:0055065] Metal ion homeostasis & 19 & 0.019086885 \\
\hline [GO:0030003] Cellular cation homeostasis & 21 & 0.031550799 \\
\hline [GO:0007268] Synaptic transmission & 23 & 0.033256699 \\
\hline
\end{tabular}

${ }^{\mathrm{a} D E G}$, differentially expressed gene; FDR, false discovery rate. 
healthy controls, indicating that obvious differences existed between the two groups.

\section{Functional enrichment analysis results for differentially expressed genes}

The functional enrichment analysis was conducted for upregulated and downregulated DEGs, respectively. The results showed that 15 and 13 terms, respectively, were significantly enriched (Table 1$)$. Cell-cycle process (FDR = 1.50E-05), cell cycle (FDR $=3.70 \mathrm{E}-05)$, cell adhesion $(\mathrm{FDR}=0.00146)$, cell motion $(\mathrm{FDR}=0.001626)$ and regulation of apoptosis $(F D R=0.00271)$ were significantly enriched among upregulated genes. Regulation of cell proliferation $(\mathrm{FDR}=3.72 \mathrm{E}-04)$, immune response $(F D R=0.001061657)$ and cellular ion homeostasis $(F D R=$ 0.010226535 ) were significantly enriched for downregulated genes. For the cell-cycle process, 30 upregulated DEGs were included, such as NIMA-related kinase 2 (NEK2), cohesin subunit (RAD21) and thrombospondin 1 (THBS1).
For regulation of cell proliferation, 48 downregulated DEGs, such as paired box 3 (PAX3), were contained.

\section{Interaction networks}

The most upregulated gene, SPP1, and the most downregulated gene, $F A B P 4$, were selected from among the DEGs. Their expression values in each sample are shown in Figure 2. Interactors of the two genes were retrieved from STRING and HitPredict, then the interaction networks were constructed (Figure 3). In total, 55 and 13 genes were included in the networks of $S P P 1$ and $F A B P 4$, respectively. The SPP1 network contained integrin $\alpha 11$ (ITGA11), integrin $\beta 5$ (ITGB5), ITGA10, ITGB3 and other genes.

\section{Functional enrichment analysis results for genes in the networks}

GeneCodis was chosen to analyze the function of all genes in the two networks. Only eight functional annotations were revealed in the network that included SPP1 (Table 2), and the most significant one was extracellular matrix

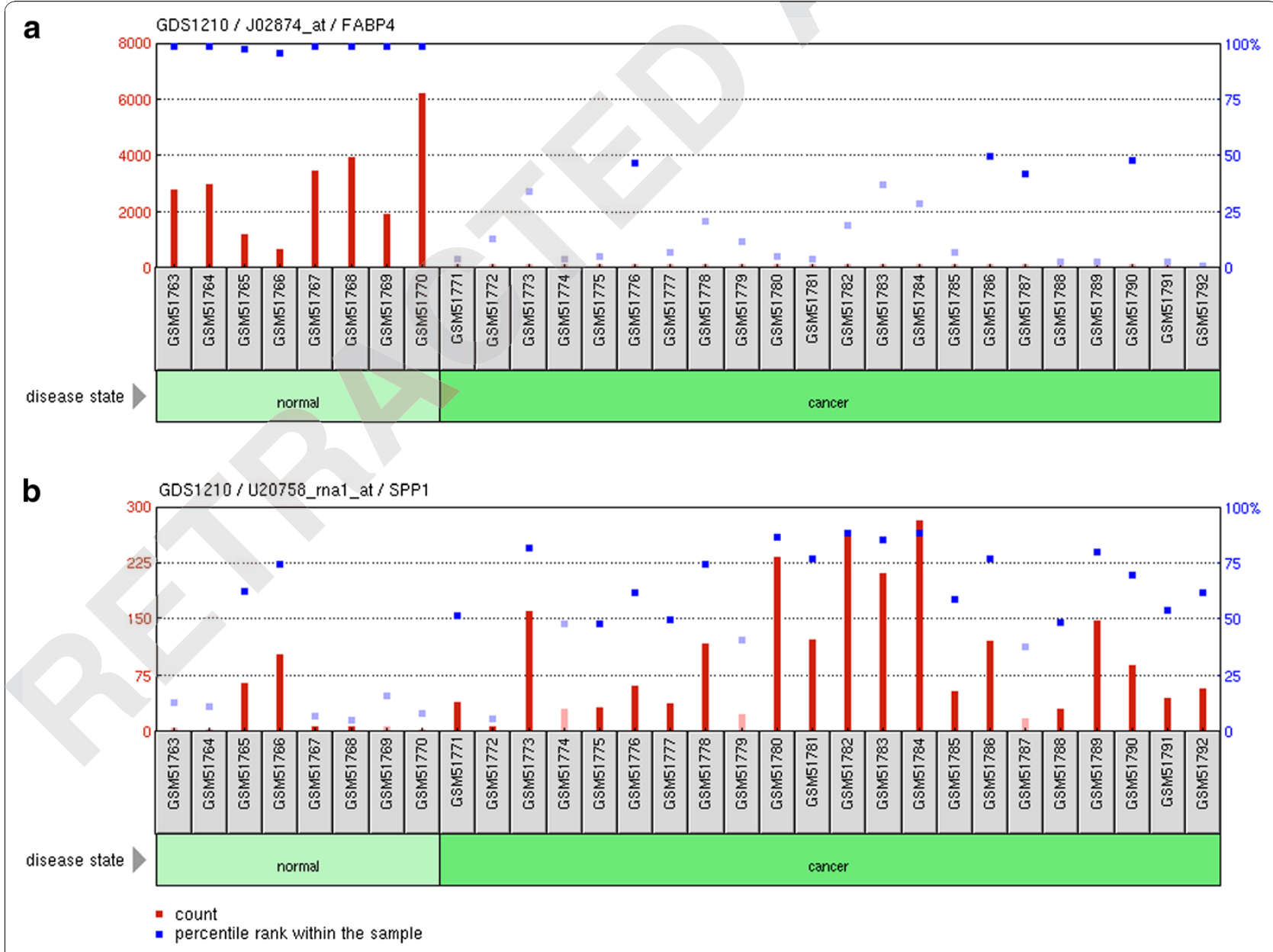

Figure 2 Gene expression levels of FABP4 (a) and SPP1 (b) in each sample. (a) FABP4 is downregulated in gastric cancer (GC) tissue. (b) SPP1 is upregulated in GC tissue. 


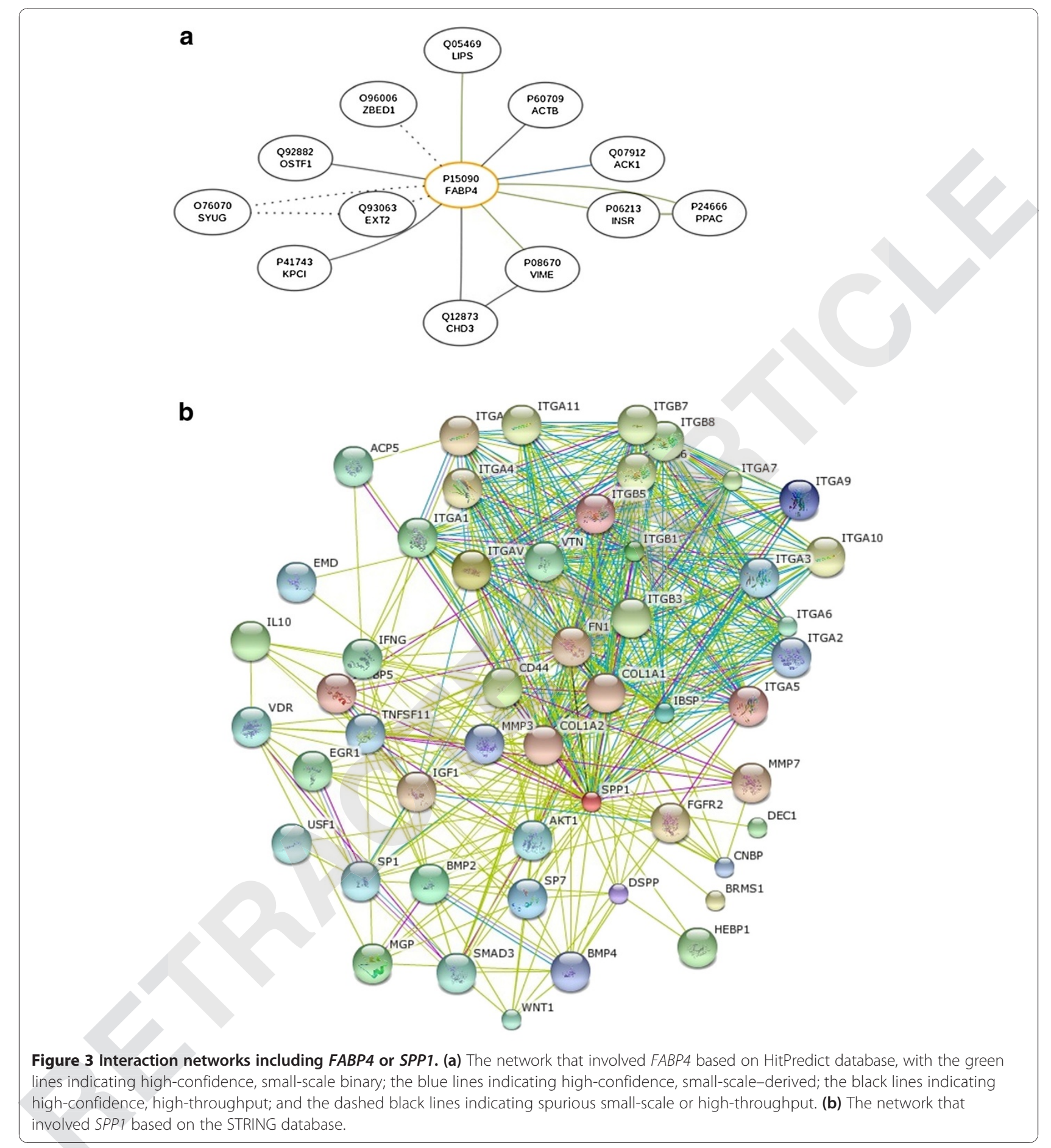

$(\mathrm{ECM})$-receptor interaction $(\mathrm{FDR}=1.01 \mathrm{E}-31) . S P P 1$ was the most overexpressed gene in the whole pathway and might play a key role in the pathogenesis of GC.

\section{Discussion}

Microarray data of GC samples and healthy controls were compared to identify the DEGs in present study. A total of 638 DEGs were obtained in GC samples. Cell- cycle process, cell adhesion, cell motion and regulation of apoptosis were significantly overrepresented in the upregulated genes according to the functional enrichment analysis, whereas regulation of cell proliferation, immune response and cellular ion homeostasis were enriched in the downregulated genes.

Proliferation, cell cycle, immune response and apoptosis are closely associated with cancer. Many factors, such as 
Table 2 Overrepresented functional annotation terms in the network including SPP1 ${ }^{\mathrm{a}}$

\begin{tabular}{lll}
\hline Gene accession number & Count & FDR \\
\hline [KEGG:hsa04512]: ECM-receptor interaction & 25 & $1.01 \mathrm{E}-31$ \\
\hline [KEGG:hsa04510]: Focal adhesion & 26 & $1.76 \mathrm{E}-23$ \\
\hline [KEGG:hsa05410]: Hypertrophic cardiomyopathy (HCM) & 20 & $1.11 \mathrm{E}-21$ \\
\hline [KEGG:hsa05414]: Dilated cardiomyopathy & 20 & $5.79 \mathrm{E}-21$ \\
\hline [KEGG:hsa05412]: Arrhythmogenic right ventricular & 19 & $8.03 \mathrm{E}-21$ \\
cardiomyopathy (ARVC) & & \\
\hline [KEGG:hsa04810]: Regulation of actin cytoskeleton & 20 & $1.11 \mathrm{E}-13$ \\
\hline [KEGG:hsa04640]: Hematopoietic cell lineage & 8 & 0.003148 \\
\hline [KEGG:hsa05200]: Pathways in cancer & 13 & 0.003491 \\
\hline aECM, extracellular matrix FDR, false discovery rate. & &
\end{tabular}

oncogenes and tumor suppressors, have been found to be involved in the regulation of cell cycle, and abnormalities in relevant genes contribute to the incidence of cancer [30]. The immune system is a critical defense, and its dysfunction results in cancer. People have put in considerable effort to disclose the mechanisms of immune escape $[31,32]$. The functional enrichment analysis results in this study confirmed the reliability of our findings, and many of them have been implicated in various cancers.

In addition, some key genes were screened as the DEGs and were involved in significant functions of the DEGs. In the cell-cycle process, for example, NEK2 encoded a serine/threonine protein kinase that was involved in mitotic regulation. It was associated with chromosome instability [33] and incidence of cancers [34]. RAD21 was involved in the repair of DNA double-strand breaks, and its deregulation was previously reported in endometrial cancer and oral squamous cell carcinoma [35,36]. Atienza et al. also indicated that suppression of $R A D 21$ gene expression can decrease growth of breast cancer cells [37]. THBS1 is a glycoprotein that mediates cell-to-cell and cell-to-matrix interactions and plays a role in tumorigenesis. Lin et al. reported that polymorphism of THBS1 rs1478604 A > G in the $5^{\prime}$-untranslated region is associated with lymph node metastasis of GC [38]. Although it regulates cell proliferation, $P A X 3$ was found to trigger neoplastic development by maintaining cells in a deregulated, undifferentiated and proliferative state, and it has become a target for cancer immunotherapy [39]. Thus, our findings might provide directions for future research.

SPP1 was the most significantly upregulated gene, and FABP4 was the most significantly downregulated gene; therefore, network analysis was conducted for the two genes to mine more information. ECM-receptor interaction was significantly enriched in the network including SPP1. In fact, ECM is a macromolecular network comprising collagen, noncollagenous glycoprotein, glycosaminoglycan, proteoglycan, elastin and others. ECM was found to influence cell survival, death, proliferation and differentiation as well as cancer metastasis [40].

In addition, several subunits of integrin were included in the SPP1 network, such as ITGA11, ITGB5, ITGA10, $I T G B 3$ and others. Integrins played important roles in cell adhesion and signal transduction. The integrin family regulated a range of cellular functions, which were crucial to the initiation, progression and metastasis of solid tumors [41]. ITGB3 was identified as a key regulator in reactive oxygen species-induced migration and invasion of colorectal cancer cells [42]. ITGB1 presented certain prognostic value for patients with GC [43]. ITGB8 silencing could reduce the potential metastasis of lung cancer cells [44]. Moreover, the ITGA2 gene C807T polymorphism was associated with the risk of GC [45]. Therefore, we thought these genes were also worthy of further research to uncover their potential effects in the diagnosis, prognosis and treatment of GC.

\section{Conclusions}

Overall, a range of DEGs were obtained through comparing gene expression profiles of GC samples with healthy controls. These genes might play important roles in the pathogenesis of $\mathrm{GC}$ according to the functional enrichment analysis, especially SPP1, which was closely associated with ECM-receptor interaction. Of course, more research is needed to confirm their potential function in clinical applications.

\section{Competing interests}

The authors declare that they have no competing interests.

\section{Authors' contributions}

YJ Conceived and designed the study and Analyzed the data; WD Wrote the paper. All authors read and approved the final manuscript.

Received: 16 July 2013 Accepted: 5 September 2013

Published: 4 October 2013

\section{References}

1. Krejs GJ: Gastric cancer: epidemiology and risk factors. Dig Dis 2010, 28:600-603.

2. Dong Y, Mei ZZ, Qian JJ, Song Y, Tian BL, Liu B, Sun ZX: [The molecular mechanism of survivin expression in activated human peripheral lymphocytes] [in Chinese]. Xi Bao Yu Fen Zi Mian Yi Xue Za Zhi 2008, 24:16-19.

3. Allgayer H, Fulda S: Molecular targeted therapy. In Hereditary Tumors: From Genes to Clinical Consequences. Edited by Allgayer H, Rehder H, Fulda S. Weinheim, Germany: Wiley-VCH Verlag GmbH \& Co. KGaA; 2009:501-514. doi:10.1002/9783527627523.ch30.

4. Ludwig JA, Weinstein JN: Biomarkers in cancer staging, prognosis and treatment selection. Nat Rev Canc 2005, 5:845-856.

5. Ryu JW, Kim HJ, Lee YS, Myong NH, Hwang CH, Lee GS, Yom HC: The proteomics approach to find biomarkers in gastric cancer. $J$ Korean Med Sci 2003, 18:505-509.

6. Jang JS, Cho HY, Lee YJ, Ha WS, Kim HW: The differential proteome profile of stomach cancer: identification of the biomarker candidates. Oncol Res 2004, 14:491-499.

7. Yasui W, Oue N, Ito R, Kuraoka K, Nakayama H: Search for new biomarkers of gastric cancer through serial analysis of gene expression and its clinical implications. Cancer Sci 2004, 95:385-392. 
8. Mitani Y, Oue N, Matsumura S, Yoshida K, Noguchi T, Ito M, Tanaka S, Kuniyasu H, Kamata N, Yasui W: Reg IV is a serum biomarker for gastric cancer patients and predicts response to 5-fluorouracil-based chemotherapy. Oncogene 2007, 26:4383-4393.

9. Oue N, Sentani K, Noguchi T, Ohara S, Sakamoto N, Hayashi T, Anami K, Motoshita J, Ito M, Tanaka S, Yoshida K, Yasui W: Serum olfactomedin 4 (GW112, hGC-1) in combination with Reg IV is a highly sensitive biomarker for gastric cancer patients. Int J Cancer 2009, 125:2383-2392.

10. Nakajima T, Yamada Y, Hamano T, Furuta K, Gotoda T, Katai H, Kato K, Hamaguchi T, Shimada Y: Adipocytokine levels in gastric cancer patients: resistin and visfatin as biomarkers of gastric cancer. J Gastroenterol 2009 44:685-690.

11. DeRisi J, Penland L, Brown PO, Bittner ML, Meltzer PS, Ray M, Chen Y, Su YA, Trent JM: Use of a CDNA microarray to analyse gene expression patterns in human cancer. Nat Genet 1996, 14:457-460.

12. Hippo Y, Taniguchi H, Tsutsumi S, Machida N, Chong JM, Fukayama M, Kodama T, Aburatani H: Global gene expression analysis of gastric cancer by oligonucleotide microarrays. Cancer Res 2002, 62:233-240.

13. Troyanskaya O, Cantor M, Sherlock G, Brown P, Hastie T, Tibshirani R, Botstein D, Altman RB: Missing value estimation methods for DNA microarrays. Bioinformatics 2001, 17:520-525.

14. Fujita A, Sato JR, de Oliveira Rodrigues L, Ferreira CE, Sogayar MC: Evaluating different methods of microarray data normalization. BMC Bioinformatics 2006, 7:469.

15. Pollard KS, Dudoit S, van der Laan MJ: Multiple testing procedures: the multtest package and applications to genomics. In Bioinformatics and Computational Biology Solutions Using $R$ and Bioconductor Statistics for Biology and Health. Edited by Gentleman R, Carey VJ, Huber W, Irizarry RA, Dudoit S. New York: Springer; 2005:249-271. doi:10.1007/0-387-29362-0_15.

16. Benjamini $Y$, Hochberg $Y$ : Controlling the false discovery rate: a practical and powerful approach to multiple testing. J R Stat Soc Series B Stat Methodol 1995, 57:289-300.

17. Eisen MB, Spellman PT, Brown PO, Botstein D: Cluster analysis and display of genome-wide expression patterns. Proc Natl Acad Sci U S A 1998, 95:14863-14868.

18. Nam D, Kim SY: Gene-set approach for expression pattern analysis. Brief Bioinform 2008, 9:189-197.

19. da Huang W, Sherman BT, Lempicki RA: Systematic and integrative analysis of large gene lists using DAVID bioinformatics resources. Nat Protoc 2009, 4:44-57.

20. Li S, Armstrong CM, Bertin N, Ge H, Milstein S, Boxem M, Vidalain PO, Han JD, Chesneau A, Hao T, Goldberg DS, Li N, Martinez M, Rual JF, Lamesch P, Xu L, Tewari M, Wong SL, Zhang LV, Berriz GF, Jacotot L, Vaglio P, Reboul J, Hirozane-Kishikawa T, Li Q, Gabel HW, Elewa A, Baumgartner B, Rose DJ, Yu H, Bosak S, Sequerra R, Fraser A, Mango SE, Saxton WM, Strome S, Van Den Heuvel S, Piano F, Vandenhaute J, Sardet C, Gerstein M, Doucette-Stamm L, Gunsalus KC, Harper JW, Cusick ME, Roth FP, Hill DE, Vidal M: A map of the interactome network of the metazoan C. elegans. Science 2004, 303:540-543.

21. Szklarczyk D, Franceschini A, Kuhn M, Simonovic M, Roth A, Minguez P, Doerks T, Stark M, Muller J, Bork P, Jensen $\sqcup$, von Mering C: The STRING database in 2011: functional interaction networks of proteins, globally integrated and scored. Nucleic Acids Res 2011, 39(Database issue):D561-D568.

22. Patil A, Nakai K, Nakamura H: HitPredict: a database of quality assessed protein-protein interactions in nine species. Nucleic Acids Res 2011, 39(Database issue):D744-D749.

23. Kerrien S, Aranda B, Breuza L, Bridge A, Broackes-Carter F, Chen C, Duesbury M, Dumousseau M, Feuermann M, Hinz U, Jandrasits C, Jimenez RC, Khadake J, Mahadevan U, Masson P, Pedruzzi I, Pfeiffenberger E, Porras P, Raghunath A, Roechert B, Orchard S, Hermjakob H: The IntAct molecular interaction database in 2012. Nucleic Acids Res 2011, 40(Database issue):D841-D846.

24. Keshava Prasad TS, Goel R, Kandasamy K, Keerthikumar S, Kumar S, Mathivanan S, Telikicherla D, Raju R, Shafreen B, Venugopal A, Balakrishnan L, Marimuthu A, Banerjee S, Somanathan DS, Sebastian A, Rani S, Ray S, Harrys Kishore CJ, Kanth S, Ahmed M, Kashyap MK, Mohmood R, Ramachandra YL, Krishna V, Rahiman BA, Mohan S, Ranganathan P, Ramabadran S, Chaerkady R, Pandey A: Human Protein Reference Database2009 update. Nucleic Acids Res 2009, 37(Database issue):D767-D772.

25. Patil A, Nakamura $\mathrm{H}$ : Filtering high-throughput protein-protein interaction data using a combination of genomic features. BMC Bioinformatics 2005, $6: 100$
26. Lodish H, Berk A, Matsudaira P, Kaiser CA, Krieger M, Scott MP, Zipurksy SL, Darnell J: Molecular Cell Biology. 5th edition. New York: WH Freeman; 2004.

27. Tabas-Madrid D, Nogales-Cadenas R, Pascual-Montano A: GeneCodis3: a non-redundant and modular enrichment analysis tool for functional genomics. Nucleic Acids Res 2012, 40(Web Server issue):W478-W483.

28. Nogales-Cadenas R, Carmona-Saez P, Vazquez M, Vicente C, Yang X, Tirado F, Carazo JM, Pascual-Montano A: GeneCodis: interpreting gene lists through enrichment analysis and integration of diverse biological information. Nucleic Acids Res 2009, 37(Web Server issue):W317-W322.

29. Carmona-Saez P, Chagoyen M, Tirado F, Carazo JM, Pascual-Montano A: GENECODIS: a web-based tool for finding significant concurrent annotations in gene lists. Genome Biol 2007, 8:R3.

30. Hunter T, Pines J: Cyclins and cancer II: cyclin D and CDK inhibitors come of age. Cell 1994, 79:573-582

31. Bennett MW, O'Connell J, O'Sullivan GC, Roche D, Brady C, Kelly J, Collins JK, Shanahan F: Expression of Fas ligand by human gastric adenocarcinomas: a potential mechanism of immune escape in stomach cancer. Gut 1999, 44:156-162.

32. He W, Liu Q, Wang L, Chen W, Li N, Cao X: TLR4 signaling promotes immune escape of human lung cancer cells by inducing immunosuppressive cytokines and apoptosis resistance. Mol Immunol 2007, 44:2850-2859.

33. Hayward DG, Fry AM: Nek2 kinase in chromosome instability and cancer. Cancer Lett 2006, 237:155-166.

34. Nakayama Kl, Nakayama K: Ubiquitin ligases: cell-cycle control and cancer. Nat Rev Cancer 2006, 6:369-381.

35. Supernat A, Łapińska-Szumczyk S, Sawicki S, Wydra D, Biernat W, Żaczek AJ: Deregulation of RAD21 and RUNX1 expression in endometrial cancer. Oncol Lett 2012, 4:727-732

36. Yamamoto G, Irie T, Aida T, Nagoshi Y, Tsuchiya R, Tachikawa T: Correlation of invasion and metastasis of cancer cells, and expression of the RAD21 gene in oral squamous cell carcinoma. Virchows Arch 2006, 448:435-441.

37. Atienza JM, Roth RB, Rosette C, Smylie KJ, Kammerer S, Rehbock J, Ekblom J, Denissenko MF: Suppression of RAD21 gene expression decreases cell growth and enhances cytotoxicity of etoposide and bleomycin in human breast cancer cells. Mol Cancer Ther 2005, 4:361-368.

38. Lin XD, Chen SQ, Qi YL, Zhu JW, Tang Y, Lin JY: Polymorphism of THBS1 rs1478604 A>G in 5-untranslated region is associated with lymph node metastasis of gastric cancer in a Southeast Chinese population. DNA Cell Biol 2012, 31:511-519.

39. Himoudi N, Nabarro S, Yan M, Gilmour K, Thrasher AJ, Anderson J: Development of anti-PAX3 immune responses: a target for cancer immunotherapy. Cancer Immunol Immunother 2007, 56:1381-1395.

40. Bijian K, Takano T, Papillon J, Khadir A, Cybulsky AV: Extracellular matrix regulates glomerular epithelial cell survival and proliferation. Am J Physiol Renal Physiol 2004, 286:F255-F266.

41. Desgrosellier JS, Cheresh DA: Integrins in cancer: biological implications and therapeutic opportunities. Nat Rev Cancer 2010, 10:9-22

42. Lei Y, Huang K, Gao C, Lau QC, Pan H, Xie K, Li J, Liu R, Zhang T, Xie N, Nai HS, Wu H, Dong Q, Zhao X, Nice EC, Huang C, Wei Y: Proteomics identification of ITGB3 as a key regulator in reactive oxygen speciesinduced migration and invasion of colorectal cancer cells. Mol Cell Proteomics 2011, 10:M110.005397.

43. Zhao ZS, Li L, Wang HJ, Wang YY: Expression and prognostic significance of CEACAM6, ITGB1, and CYR61 in peripheral blood of patients with gastric cancer. J Surg Oncol 2011, 104:525-529.

44. $\mathrm{Xu} \mathrm{Z}, \mathrm{Wu} \mathrm{R}$ : Alteration in metastasis potential and gene expression in human lung cancer cell lines by ITGB8 silencing. Anat Rec (Hoboken) 2012, 295:1446-1454.

45. Chen J, Liu NN, Li JQ, Yang L, Zeng Y, Zhao XM, Xu LL, Luo X, Wang B, Wang XR: Association between ITGA2 C807T polymorphism and gastric cancer risk. World J Gastroenterol 2011, 17:2860-2866.

\section{doi:10.1186/2047-783X-18-37}

Cite this article as: Jin and Da: Screening of key genes in gastric cancer with DNA microarray analysis. European Journal of Medical Research 2013 18:37 